\title{
Application of discrete damage mechanics for determination of the crack density in composite laminates
}

\author{
Milan Žmindák ${ }^{1, *}$, Eva Kormaníková ${ }^{2}$, Pavol Novák ${ }^{1}$, Josef Soukup ${ }^{3}$, Kamila Kotrasová2 \\ ${ }^{1}$ Department of Applied Mechanics, Faculty of Mechanical Engineering, University of Zilina, \\ Univerzitna 1, 01026 Zilina, Slovakia \\ ${ }^{2}$ Technical University of Kosice, Faculty of Civil Engineering, Vysokoskolska 4, 04200 Kosice, \\ Slovakia \\ ${ }^{3}$ J. E. Purkyne University in Usti nad Labem, Faculty of Mechanical Engineering, Pasteurova 3334/7, \\ 40096 Usti nad Labem, Czech Republic
}

\begin{abstract}
The finite element method (FEM) is one of the most widely and most popular numerical methods for analyzing damage of composite structures, In this paper discrete damage mechanics (DDM) is used to predict inter-laminar transverse and shear damage initiation and evolution in terms of the fracture toughness of the laminate. ANSYS commercial software is used for analysis of layered plate composite structure reinforced with long unidirectional fibers with Carbon/Epoxy material. Because ANSYS does not have a built-in capability for calculating crack density, we have to use plagin. A methodology for determination of the fracture toughness is based on fitting DDM model and these data are obtained from literature. Also, prediction of modulus vs. applied strain is contrasted with ply discount results and the effect of in situ correction of strength is highlighted. Evaluation of matrix cracking detected in lamina has been solved using return mapping algorithm.
\end{abstract}

\section{Introduction}

The term damage is commonly used in different ways in the field of composites to describe lack of adhesion, debonding of the fiber from its matrix, delamination, or breakage of the fiber, etc. Fracture and failure are one of the challenging issues in solid mechanics. Under high levels of mechanical loads, fracture can occur in different materials ranging from metals, ceramics to polymers and composites. Depending on the microstructure of the materials, fracture can originate from voids, microcracks, movement of dislocations, de-bonding and even structural effects such as buckling. The problem becomes more complex in the case of composite materials $[1,2]$. In general, composite materials are composed by stacking different layers of materials. Each layer consists of two different constituents.

\footnotetext{
*Corresponding author: milan.zmindak@ fstroj.uniza.sk
} 
There are several methodologies to model the failure of composite materials which have been used in the scientific literature, as failure criteria (usually stress based), continuum damage mechanics (CDM) models, crack opening displacements methods, etc. [3].

Alternatives to CDM include: micromechanics of damage, crack opening displacement methods, computational micromechanics, and synergistic methods. While CDM homogenizes the damage and treats it phenomenologically, the alternative methods attempt to represent the actual geometry and characteristics of damage. Accurate physical representation of the fracture phenomena is the most salient feature of alternative models.

In laminated composites, matrix cracks grow parallel to the fiber orientation due to the inability of the crack front to break the fibers [4]. These cracks reduce the stiffness of the cracked lamina, which then sheds its share of the load onto the remaining laminas [5]. Since the actual geometry of the cracks is modelled, the formulation is called discrete damage mechanics (DDM). These models are able to predict accurately the strain at which the first crack appears, how crack density evolves as a function of applied strain, and how stress are redistributed in the laminate due to degradation of the mechanical properties of a cracked lamina.

\section{Theory background}

Models for flexural stiffness reduction due to transverse matrix cracks confront more difficulties than the models for in-plane stiffness reduction. Also, as unsymmetrical laminates present extension-bending coupling, modeling such laminates demands specific formulations. Therefore, just a limited number of works can be found on flexure deformations compared with those on in-plane deformations.

Most practical laminates are symmetric and the most efficient use of them is by designing the structure to be loaded predominantly with membrane loads. Therefore, the solution presented here is for a symmetric laminate under membrane loads. In this case,

$$
\frac{\partial w^{(i)}}{\partial x_{1}}=\frac{\partial w^{(i)}}{\partial x_{2}}=0, \sigma_{z}^{i}=0
$$

where $u(x, y, z), \mathrm{v}(x, y, z), w(x, y, z)$ are displacements of a point in lamina $i$ as a function of the coordinates $x_{1}, x_{2}$. The basic steps of the DDM model for transverse tension and in-plane shear damage are listed below.

\subsection{Discrete damage model}

To study damage localization, the DDM is selected. DDM model is a semi-analytical linearelastic fracture mechanics (LEFM) model [6]. The model is able to predict the crack density $\lambda=1 / 2 l$ where $2 l$ is the distance between each pair of cracks (Fig. 1 ). The crack density is only state variable needed to represent the state of damage in the cracked lamina.

\subsection{Solution algorithm}

The solution algorithm is based on three main steps: 1) strain steps, 2) laminate-iterations, and 3) lamina-iterations. The state variables for the laminate are stored in the array of crack densities for all laminas $i$ and the membrane strain $\varepsilon$. At each strain load step, the strain on the laminate is increased and the laminas are checked for damage. The basic methodology of the DDM modelling for transverse tension and in-plane shear damage is: 
- In each lamina $i$, the state variable is the crack density $\lambda_{i}$. The set of crack densities for the laminate is denoted by $\lambda=\lambda_{i}, i=1, \ldots, N$, where $N$ is the number of laminas in the laminate.

- The independent variable is the midsurface1 strain $\varepsilon=\left\{\varepsilon_{1}, \varepsilon_{2}, \gamma_{12},\right\}^{T}$.

- The damage activation function is

$$
g=(1-r) \sqrt{\frac{G_{I}\left(\lambda_{1} \epsilon\right)}{G_{I c}}}+r \frac{G_{I}\left(\lambda_{1} \epsilon\right)}{G_{I c}}+\frac{G_{I I}\left(\lambda_{1} \epsilon\right)}{G_{I I}}-1 \leq 0, r=\frac{G_{I c}}{G_{I I c}}
$$

where $g \leq 0$ represents the undamaging domain.

- The return -mapping algorithm (RMA) [7] calculates the increment (decrement) of crack density $\lambda$ as

$$
\Delta \lambda_{k}=-g_{k} / \frac{\partial g_{k}}{\partial \lambda}
$$
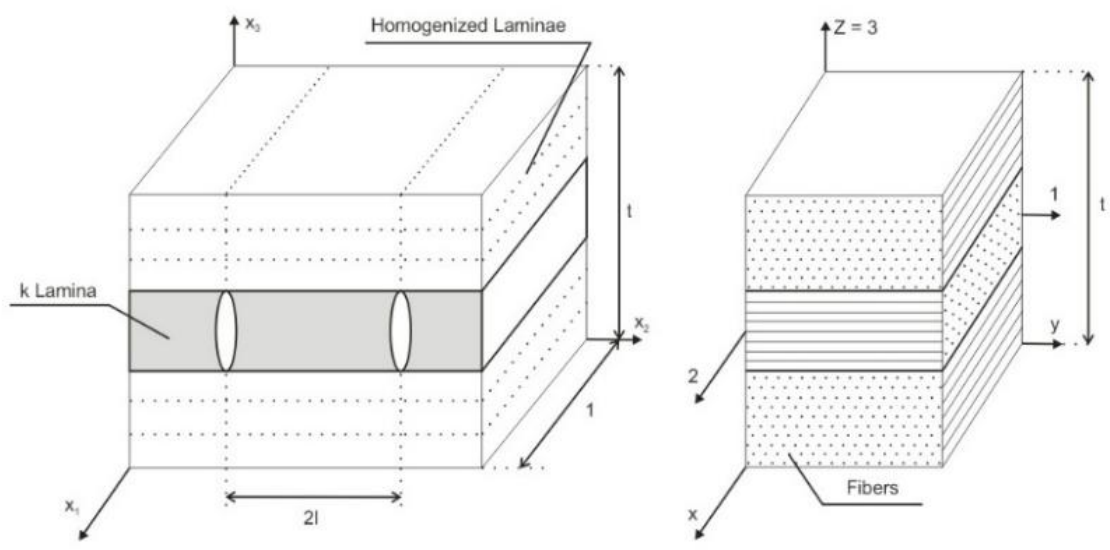

Fig. 1. Representative volume element used by DDM [3].

A RMA achieves this by integrating until $g=0$ and updating the crack density with iterative increments calculated as $\Delta \lambda=-g / \frac{\partial g}{\partial \lambda}$.

- The damage threshold is represented by the energy release rate (ERR) $G_{I c}, G_{I I c}$.For a given value of strain, the calculated values od ERR are monotonically decreasing functions $\lambda$.

- Crack density grows until saturation, defined as $\lambda_{\text {lim }}=1 / t_{k}$, where $t_{k}$ is the thickness of lamina $k$.

\section{Problem description}

Consider a $\left[0 / 90_{8} / 0 / 90_{8} / 0\right]$ laminate manufactured from IM7/8552. Unidirectional Graphite/Epoxy Prepreg with properties given in Table.1 are subjected to a membrane strain $\varepsilon_{x} \neq 0, \varepsilon_{y}=\gamma_{x y}=0$. The dimensions of the model are $a$ and $b$ along the $x$ and $y$ directions, respectively. We have calculate and visualize the crack density in lamina $k=2$ for an uniform applied strain $\varepsilon_{x}=0.48 \%$. Then it is necessary calculate the average laminate stress 
$\sigma_{x}=N_{x} / h$, where $N_{x}$ and $h$ are the stress resultant and the total laminate thickness, respectively.

\subsection{The DDM plagin}

First, since ANSYS does not have a built-in capability for calculating crack density, we have to use a plugin. In this case, it necessary to implement material subroutine for a state of plane stress for DDM. The DDM plugin is available in [1,USERMATLib.DLL].

Table 1. Material properties

\begin{tabular}{|c|c|c|}
\hline $\begin{array}{c}\text { Elastic and strength } \\
\text { properties }\end{array}$ & Symbol & Value \\
\hline Longitudinal modulus & $E_{1}[\mathrm{GPa}]$ & 161 \\
\hline Transverse modulus & $E_{2}[\mathrm{GPa}]$ & 14.39 \\
\hline In-plane shear modulus & $G_{12}[\mathrm{GPa}]$ & 5.2 \\
\hline In-plane Poisson's ratio & $v_{12}$ & 0.467 \\
\hline $\begin{array}{c}\text { Intralaminar Poisson's ratio } \\
G_{23}=E_{2} / 2 /\left(1+\gamma_{23}\right) .\end{array}$ & $v_{23}$ & 0.41 \\
\hline Lamina thickness & $t_{k}[\mathrm{~mm}]$ & 0.15 \\
\hline $\begin{array}{c}\text { Critical value of ERR in mode } \\
\text { I }\end{array}$ & $G_{I c}\left[\mathrm{~kJ} / \mathrm{m}^{2}\right]$ & 0.17 \\
\hline $\begin{array}{c}\text { Critical value of ERR in mode } \\
\text { II. Use } G_{I I c}>4 G_{I c} \text { if data is } \\
\text { not available }\end{array}$ & $G_{I I c}\left[\mathrm{~kJ} / \mathrm{m}^{2}\right]$ & 0.23 \\
\hline $\begin{array}{c}\text { Longitudinal coefficient of } \\
\text { thermal expansion }\end{array}$ & $C T E_{1}\left[1 \mathrm{E}-6 /{ }^{\circ} \mathrm{C}\right]$ & 0.9 \\
\hline $\begin{array}{c}\text { Transverse coefficient of } \\
\text { thermal expansion }\end{array}$ & $C T E_{2}\left[1 \mathrm{E}-6 /{ }^{\circ} \mathrm{C}\right]$ & 28.8 \\
\hline $\begin{array}{c}\text { Change in temperature from } \\
\text { the temperature at which } G_{I c}, \\
G_{I I c}, \text { were measured to the } \\
\text { operating temperature }\end{array}$ & $\Delta T\left[{ }^{\circ} \mathrm{C}\right]$ & 0 \\
\hline $\begin{array}{c}\text { Lamina orientation with } \\
\text { respect to the laminate c.s. }\end{array}$ & $\theta_{k}$ & 0 \\
\hline
\end{tabular}

We note that the plugin requires an input of $3+9 N$ material properties $G_{I c}, G_{I I c}, \Delta T, E_{1}$, $E_{2} G_{12}, \gamma_{12}, \gamma_{23}, \alpha_{1}, \alpha_{2}, \theta_{k}, t_{k}$, where $N$ is the number of laminas in the symmetric part of the laminate, i.e., in one half of the LSS. The properties are ordered as follows, starting with the first lamina, $k=1$ (bottom surface), and continuing until the lamina $N$ (middle surface). In this study we use ANSYS 14.0, Microsoft Visual studio 2008 and Fortran Intel 11.1 operating under a Windows system 7.0.

Next, the plugin calculates $3 \mathrm{~N}$ state variables, starting with the first lamina, $k=1$ (bottom surface), and continuing until the lamina $N$ (middle surface):

$\lambda_{k} \quad$ - Crack density in lamina $k$.

$D_{2} \quad$ - Transverse damage, lamina k.

$D_{6} \quad$ - Shear damage, lamina k.

We note that ANSYS implementation of DDM is shown to be independent of mesh density, element type and size and number of nodes. 


\subsection{Parametric modelling in ANSYS Parametric Design Language (APDL)}

Second, the model is set parametrically, as follows. The input parameters are:

- The applied strain at the end of the time step.

- The initial crack density.

- The shell dimensions.

- The ply thickness.

- The number of laminas.

- The number of properties, which for DDM is calculated in terms of the number of laminas.

Next, APDL commands are used to specify the element type, the laminate stacking sequence (LSS) $\left[0 / 90_{8} / 0 / 90_{8} / 0\right]$, the elastic properties with MP command and the material strengths with TB command (Table 1). Since the strain field inside the shell is uniform in both direction $(x, y)$, therefore we use only PLANE182 element to model a unit domain with dimensions $a=100 \times b=100 \mathrm{~mm}$. Then, set up a uniform deformation $\varepsilon_{x}$ using displacement boundary conditions.

\section{Numerical results}

The general postprocessor (/POST1) can be used to produce a contour plot of state variables. The crack density $\lambda=0.245864 \mathrm{crack} / \mathrm{mm}$, in layer $2(S V A R=4)$, for applied strain $\varepsilon_{x}=$ $0.48 \%$ is uniform over the $x-y$ domain. The crack density in $x$-direction has linear course and the TIME $=0.24$ was selected purposely to coincide with the initiation of damage at $\varepsilon_{x}=$ $0.48 \%$ (Fig.2).

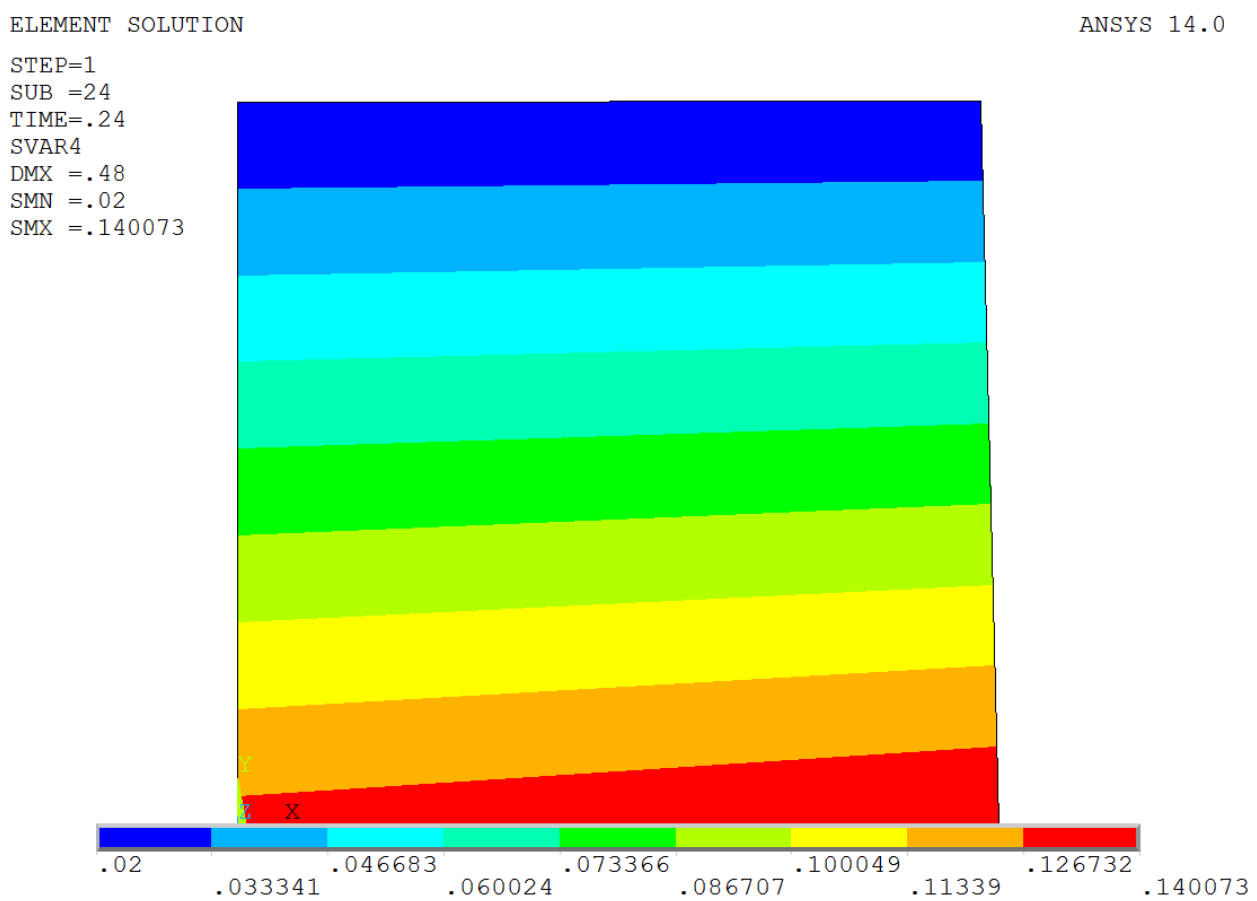

Fig.2. Linear crack density $\lambda=0.140073 \mathrm{crack} / \mathrm{mm}$, in layer $2(S V A R=4)$, for applied strain $\varepsilon_{x}=0.48 \%$ on the lower surface and $\varepsilon_{x}=0.24 \%$ on the right surface. 
The time postprocessor (/POST26) can be used to produce a time plot of state variables. Fig. 3 shows course of average laminate stress $\sigma_{x}=N_{x} / h$ on dependence applied strain $\varepsilon_{x}$. Fig. 4 shows average laminate stress $\sigma_{x}=N_{x} / h$ for deformation $\varepsilon_{x}=0.48 \%$ on the lower surface and for $\varepsilon_{x}=0.24 \%$ on the right surface

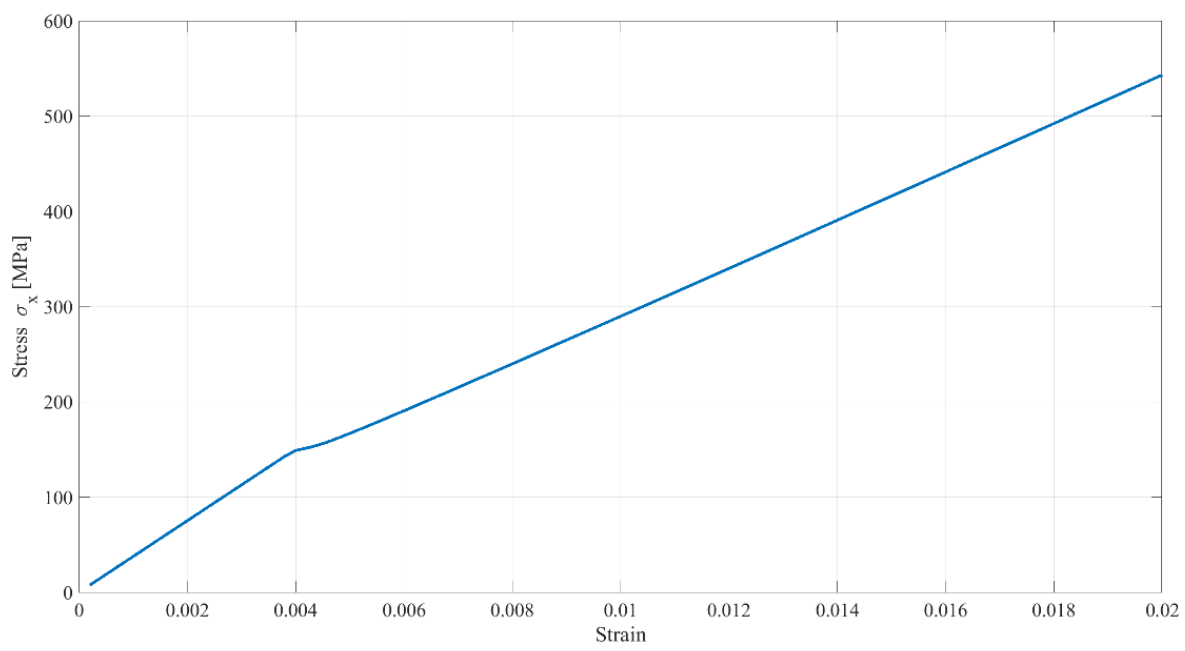

Fig. 3. Average laminate stress $\sigma_{x}=N_{x} / h$ for applied strain $\varepsilon_{x}$.

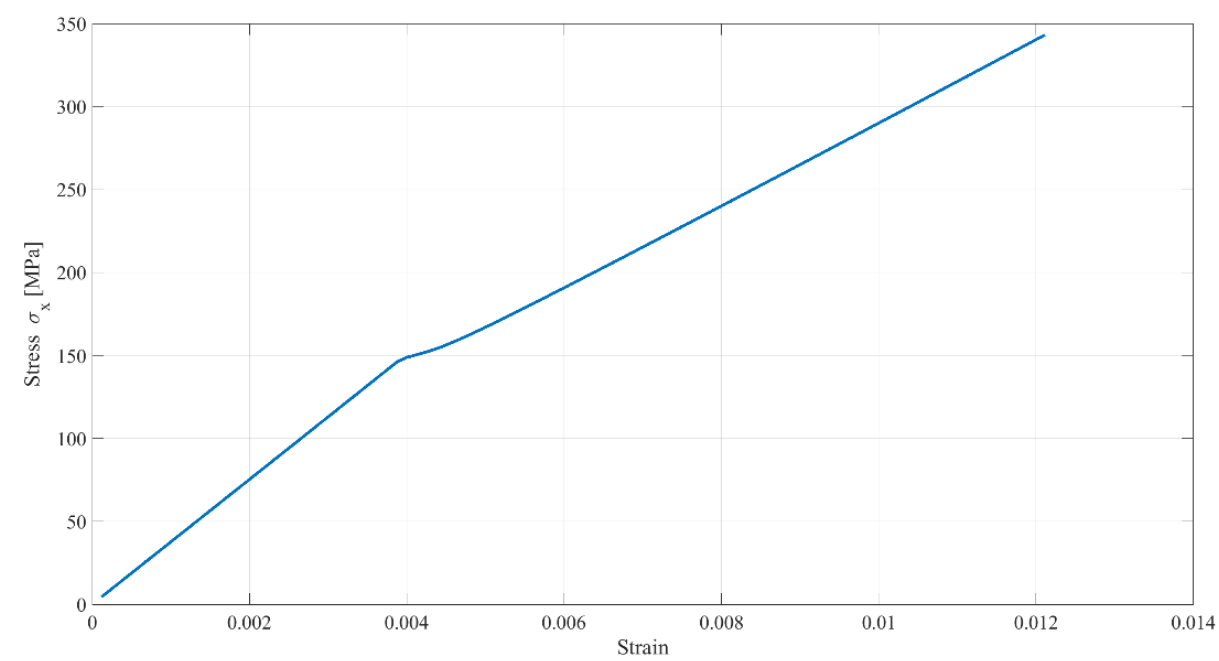

Fig.4. Average laminate stress $\sigma_{x}=N_{x} / h \quad \varepsilon_{x}=0.48 \%$ on the lower surface and $\varepsilon_{x}=0.24 \%$ on the right surface.

\section{Conclusion}

The procedure is explained to determine the crack density in composite laminates using ANSYS. The damage parameters of DDM can be calculated from measured laminate stiffness degradation but they are not directly measurable parameters, as it is, for example, the crack density. DDM can predict reduction of stiffness, and uses damage parameters to do, but also crack density as a function of load or applied strain is predicted. DDM predicts 
modulus reduction and crack density as a function of load or applied strain. Unlike classical damage variables based on modulus reduction, crack density is a true state variable, which additionally could be correlated with the permeability of the composite. DDM uses the critical energy release rate parameters to predict both initiation and crack propagation.

This work was supported by the Scientific Grant Agency of the Ministry of Education of Slovak Republic and the Slovak Academy of Sciences under Projects VEGA 1/0374/19 and VEGA 1/0199/20.

\section{References}

1. E.J Barbero, Finite Element Analysis of Composite Materials Using ANSYS - Second Edition (CRC Press, 2014)

2. O. Stalmach, V. Dekys, F. Barnik, J. Simon, MATEC Web of Conferences, 244, 01026 (2018)

3. M.M. Moure, S. Sanchez-Saez, E. Barbero, E.J. Barbero, Composites: Part B, 66, 224232 (2014)

4. E.V. Iarve, D.H. Mollenhauer, Numerical modelling of failure in Advanced Composite Materials. P.P. Camanho, S.R. Hallet (Eds.), (2015)

5. N. D. Barulich, L.A. Godoy, P.M. Dardati, Composite Structures. 185, 561-572 (2018)

6. E.J. Barbero, M. Shahbazi, Theoretical and Applied Fracture Mechanics, 92 (2017)

7. M. Žmindák, M Dudinský, Composites and their properties. N. Hu (Eds.) (Intech 131152, 2012) 